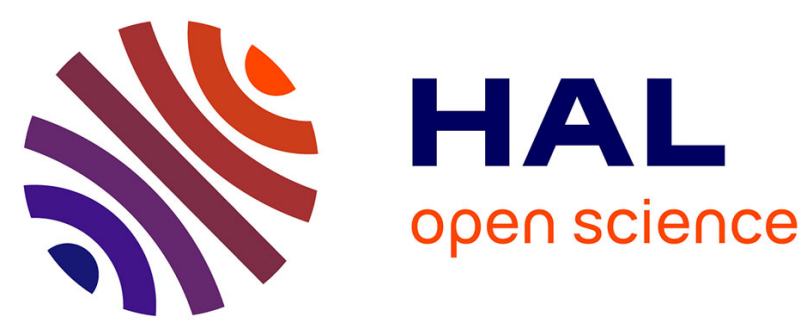

\title{
Development of a chalcogenide glass fiber device for in situ pollutant detection
}

Karine Michel, B. Bureau, C. Pouvreau, Jean-Christophe Sangleboeuf, C. Boussard-Plédel, Thierry Jouan, Tanguy Rouxel, J. L. Adam, K. Staubmann, H. Steinner, et al.

\section{To cite this version:}

Karine Michel, B. Bureau, C. Pouvreau, Jean-Christophe Sangleboeuf, C. Boussard-Plédel, et al.. Development of a chalcogenide glass fiber device for in situ pollutant detection. Journal of NonCrystalline Solids, 2003, 326, 10.1016/S0022-3093(03)00438-1 . hal-01148183

\section{HAL Id: hal-01148183 https://hal.science/hal-01148183}

Submitted on 18 Aug 2020

HAL is a multi-disciplinary open access archive for the deposit and dissemination of scientific research documents, whether they are published or not. The documents may come from teaching and research institutions in France or abroad, or from public or private research centers.
L'archive ouverte pluridisciplinaire HAL, est destinée au dépôt et à la diffusion de documents scientifiques de niveau recherche, publiés ou non, émanant des établissements d'enseignement et de recherche français ou étrangers, des laboratoires publics ou privés. 


\title{
Development of a chalcogenide glass fiber device for in situ pollutant detection
}

\author{
K. Michel ${ }^{\mathrm{a}}$, B. Bureau ${ }^{\mathrm{a}, *}$, C. Pouvreau ${ }^{\mathrm{b}}$, J.C. Sangleboeuf ${ }^{\mathrm{b}}$, \\ C. Boussard-Plédel a, T. Jouan ${ }^{\text {a }}$, T. Rouxel ${ }^{\text {b }}$, J.-L. Adam ${ }^{\text {a }}$, K. Staubmann ${ }^{\text {c,1 }}$, \\ H. Steinner ${ }^{\text {d,1 }}$, T. Baumann ${ }^{\text {e, },}$, A. Katzir ${ }^{\mathrm{f}, 1}$, J. Bayona ${ }^{\text {g,1 }}$, W. Konz ${ }^{\text {h,1 }}$ \\ a Laboratoire des Verres et Céramiques UMR-CNRS 6512, Université de Rennes 1, Campus de Beaulieu, 35042 Rennes cédex, France \\ ${ }^{\mathrm{b}}$ LARMAUR UPRES-JE 2310, Université de Rennes 1, Campus de Beaulieu, 35042 Rennes cédex, France \\ ${ }^{\mathrm{c}}$ Institut fur Wasservorsorge, Gewasseokologie und Abfallwirtschaft, University of Agricultural Sciences, \\ Muthgasse 18, A-1190 Vienna, Austria \\ d Institute of Analytical Chemistry, Vienna University of Technology, Getreidemarkt 9/151, A-1060 Vienna, Austria \\ e Institut fur Wasserchemie und Chemische Balneologie, Munich University of Technology, D-81377 Munich, Germany \\ ${ }^{\mathrm{f}}$ School of Physics, Tel Aviv University, IL-69978 Tel Aviv, Israel \\ ${ }^{\mathrm{g}}$ Department of Chemistry, CID-CSIC, 08034 Barcelona, Spain \\ ${ }^{\mathrm{h}}$ Fraunhofer Institut of Physical Measurement Techniques, Heidenhosfstr. 8, D-79110 Freiburg, Germany
}

\begin{abstract}
Infrared optical fibers based on chalcogenides are investigated to optimize their response and they are used for in situ detection of pollutant in groundwater. The pilot scale measurements proved that a $\mathrm{Te}_{2} \mathrm{As}_{3} \mathrm{Se}_{5}$ (TAS) glass fiber permits access to the absorption line positions of classic pollutants like tetrachloroethylene or dichlorobenzene. Moreover, it has been shown that the original design of the fiber enables detection of weak concentrations of pollutants down to $1 \mathrm{ppm}$. For experiments in 'real world' conditions, optical fibers must be durable under various natural working conditions in ground water. The preliminary mechanical tests demonstrate that efforts have to be done while drawing the fiber to improve their resistance. Nevertheless, at this time, a polymer coated TAS glass fiber is already a useful tool to collect some infrared spectra in landfill.
\end{abstract}

\footnotetext{
* Corresponding author. Tel.: +33-2 232356 19/65 73; fax: +33-2 23235611 .

E-mail address: bruno.bureau@univ-rennes1.fr (B. Bureau).

${ }^{1}$ IMSIS European contract partners.
}

\section{Introduction}

A new generation of optical fibers has been developed based on the large transparency domain of an original family of IR chalcogenide glasses transmitting from 2 to $14 \mu \mathrm{m}$. These fibers can be used as chemical sensors in many fields of application: biology, medicine, food, environment 
[1-4]. In this case, the aim is to make a prototype mid-infrared sensor system for the determination of organic pollutants in ground water. For this, chalcogenide glass fiber is employed, on the one hand, to transmit the IR beams from the spectrometer to the polluted zone, and on the other hand, as a probe by inserting a part of the fiber, called the sensing zone, into the studied environment. So, the fiber probes are very practical because we have to characterize some pollutants in groundwater remotely. The abilities of the fiber must be optimized because of a very precise schedule of conditions. We need long cables to transmit the beams, high sensitivity for the sensing zone because the pollutant concentrations are usually lower than $10 \mathrm{mg} \mathrm{dm}^{-3}$, large transmission windows to detect, for example, $\mathrm{C}-\mathrm{Cl}$ bonds, and an efficient device to protect the fiber. The first pilot scale test was carried out in an artificial aquifer system that simulated the landfill groundwater. The optical sensitivity of the fiber has been confirmed but it appeared that the mechanical resistance of the sensor must be reinforced to make it easy to handle in such conditions. To achieve this goal some preliminary mechanical characterization tests were carried out on the fibers.

In this paper, the steps of the sensor improvements will be presented together with the detection results obtained during the pilot scale tests. The first mechanical characterization results will be also described.

\section{Experimental}

The fibers were fabricated from the chalcogenide glass composition $\mathrm{Te}_{2} \mathrm{As}_{3} \mathrm{Se}_{5}$. This composition was chosen in the Te, As, Se ternary diagram according to the following specifications: a large optical window covering the spectral region 2 to 18 $\mu \mathrm{m}$, an excellent resistance to devitrification during the drawing process to avoid optical scattering losses, keeping good thermomechanical properties (glass transition temperature $T_{\mathrm{g}}=137^{\circ} \mathrm{C}$ ).

Raw materials with 99.999 elemental abundance were used for glass preparation as detailed in a previous paper [5]. Selenium and arsenic were further purified of remaining oxygen and hydrogen by the volatilization technique by heating them at respectively 240 and $290{ }^{\circ} \mathrm{C}$ under vacuum for several hours. As for tellurium, the oxide surface layers were dissolved in liquid $\mathrm{HBr}$. After this treatment, the required amounts of Te, As and Se were sealed in a silica tube under vacuum and the mixture was distilled and then maintained at 700 ${ }^{\circ} \mathrm{C}$ for $12 \mathrm{~h}$ in a rocking furnace to ensure a good homogenization of the liquid. Then the ampoules were quenched in water and annealed near the glass transition temperatures $\left(T_{\mathrm{g}}\right)$ to avoid permanent mechanical stresses on cooling. In this manner chalcogenide glass rods were obtained in sizes of about $1 \mathrm{~cm}$ diameter and $10 \mathrm{~cm}$ length. The fibers were made from these rods using a drawing tower. Glass cylinders were heated up to the softening temperature, and drawn to the appropriate diameter by selecting the best parameter combination of viscosity and drawing speed. For the environment applications, a polymer coating was applied on the fiber to protect and prevent it from breaking. Furthermore, it has already been shown that the sensing ability of the sensor increases when its diameter decreases and when its length increases [6]. So, the diameter of the fiber was locally reduced to create a $20 \mathrm{~cm}$ long tapered sensing zone which was to be brought in contact with the polluted water. This goal was achieved by accelerating on line the speed during the drawing process. Typically, the fiber had a diameter of 400 $\mu \mathrm{m}$ in the transportation section and $100 \mu \mathrm{m}$ in the sensing zone. Of course, at the end, the protective polymer is removed from this sensing zone.

\section{Results and discussion}

\subsection{Environment pilot scale tests}

The objective of the pilot scale test was the development and application of a fiber optic midinfrared sensor for the monitoring of contaminants in groundwater and soil. For this, a unique chalcogenide glass fiber aimed at transmitting the IR beams from the spectrometer to the polluted zone and also at probing by dumping the fiber in the test zone. The light propagated in the fiber by total internal reflection (TIR). TIR occurs at the 


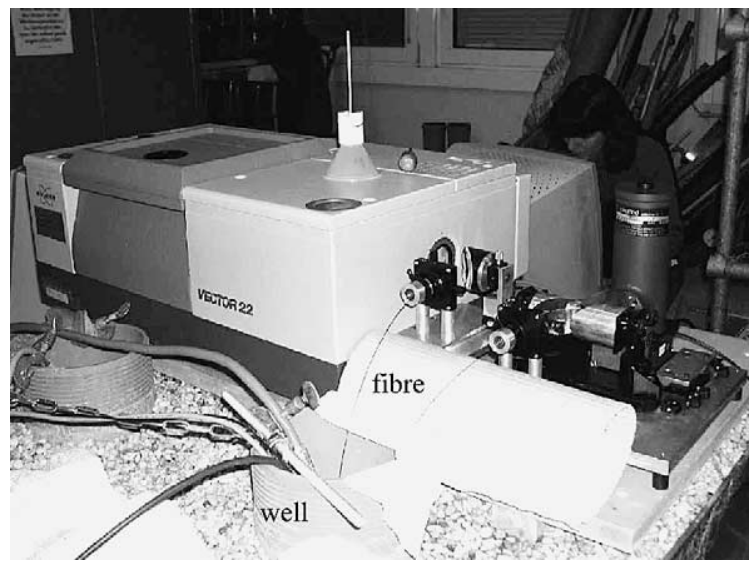

Fig. 1. Experimental setup of the pilot scale tests exhibiting the TAS glass fiber connected to the FTIR spectrometer. The fiber dips in the tank thanks to the well.

interface, for the rays whose angles of incidence are over the critical angle, as long as the medium surrounding the fiber is weakly absorbent (for example: air). When chemical species are brought into contact with the fiber, the IR optical rays are partially absorbed at the interface following the attenuated total reflection (ATR) rules. For optical fiber sensors the fiber evanescent wave spectroscopy (FEWS) is preferable to avoid confusion with ATR crystal probe devices.

Pilot scale tests were conducted in an artificial aquifer system (tank filled with simulated polluted water) in December 2001 (Fig. 1). The measurement experimental setup consisted of a FTIR spectrometer (Brucker V22), coupled with the fiber $(2 \mathrm{~m})$, and a cooled mercury-cadmium-telluride detector. The tank contained $1 \mathrm{~m}^{3}$ of water and was filled with gravel. The contaminants were dissolved in $10 \mathrm{dm}^{3}$ of water using methanol as a dissolving agent. During the migration of the contaminants through the tank, the signals of the sensor systems were logged to a PC. Simultaneously, samples for chemical analysis were taken from the wells at periodic intervals. The measurement series was initiated using tetrachloroethylene $\left(\mathrm{C}_{2} \mathrm{Cl}_{4}\right)$ as the pollutant. IR spectra, from 800 to $4000 \mathrm{~cm}^{-1}$, encompass numerous absorption bands due to water, carbon dioxide, $\mathrm{Se}-\mathrm{H}$ and $\mathrm{O}-\mathrm{H}$ bonds. The $\mathrm{C}_{2} \mathrm{Cl}_{4}$ absorption lines were clearly present zooming in the relevant spectral range

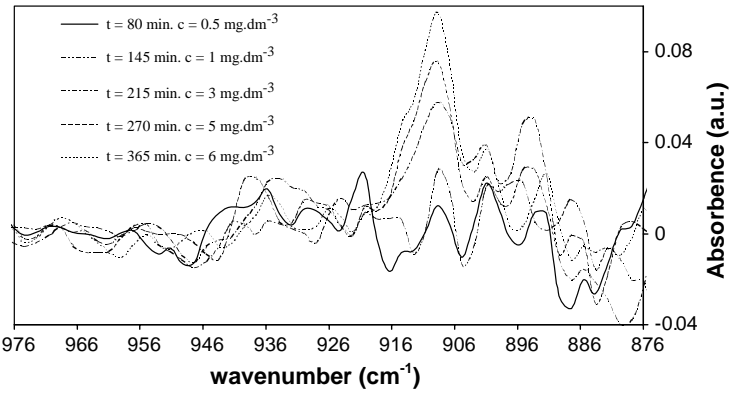

Fig. 2. Evolution of the absorbence of the $\mathrm{C}_{2} \mathrm{Cl}_{4}$ line at 908 $\mathrm{cm}^{-1}$ for a length of immersion of the fiber equal to $20 \mathrm{~cm}$.

(Fig. 2). As expected, the absorption line intensity $\left(908 \mathrm{~cm}^{-1}\right)$ increased linearly versus time and so versus the concentrations. For example, after 80 min, the concentration was equal to $0.5 \mathrm{mg} \mathrm{dm}^{-3}$ (absorbance was 0.01) while after $365 \mathrm{~min}$ it reached $6 \mathrm{mg} \mathrm{dm}^{-3}$ (absorbance was 0.1). From these first measurements, it appears that a TAS glass fiber permits access to the absorption band positions of classic pollutants thanks to the large window of transmission of the glass, and overall it has been proved that the original design of the fiber enabled detection of very weak concentrations (down to about $1 \mathrm{mg} \mathrm{dm}^{-3}$ ). Nevertheless, these optical fibers should be durable under various natural working conditions in ground water and soil. At this time, the fibers, even protected by polymer, were not easily handled because of their weak mechanical properties. That is the reason why mechanical studies were conducted in terms of mechanical testing under tensile modes, coupled to a statistical-probabilistic approach based on Weibull theory.

\subsection{Mechanical characterization}

No polymer coating was applied on the fiber for the mechanical tests. Qualitative and quantitative fractographic analysis were performed to assess defect types, shapes and orientations regarding the applied stresses. The measurement of elastic constants of materials (Young's and shear moduli) using ultrasonic tests was based on the propagation of acoustic waves within the material under investigation. The obtained Young's moduli was $E=18 \pm 0.3 \mathrm{GPa}$ and the shear moduli 
$G=7 \pm 0.2 \mathrm{GPa}$. Poisson's ratio, equal to 0.3 , is consistent with values obtained in the case of other brittle materials. Indentation tests were performed with a Vicker's indentor on specimens analogous to the ultrasonic ones. A constant load was applied to one face of the cylinder, using a pyramidal indentor, for $20 \mathrm{~s}$. For glasses, after removing the high preset load, two marks usually remain: the mark of the indentor helps to determine the hardness of the material, $H=1.3 \pm 0.2 \mathrm{GPa}$, and the crack extending from the edges of the indentor mark, whose length enables the estimate of the fracture toughness: $K_{\mathrm{c}}=0.17 \mathrm{MPa} \sqrt{\mathrm{m}}$ corresponding to hardness and toughness values recorded in the case of chalcogenide glasses. Tensile tests were carried out on an Adamel testing machine, suitable for tests on fibers. The grips were self-aligned. At the end of tests, cracked specimens were carefully checked using optical and electronic microscopies. Results of statistical tests were based on 30 conclusive tests, i.e. 30 fibers that failed within the gauge length. Statistical treatment was performed using the classical Weibull theory that defines the probability of cumulative failure. Weibull plots are depicted in Fig. 3 for TAS fibers. The tensile strength (ranging between 25 and 30 $\mathrm{MPa}$ at most) is low when compared to oxide glass fibers [7]. Qualitative fractography analysis enable us to observe the fractured surface of TAS optical fiber as depicted in Fig. 4. The presence of flaws on the fiber surface is clearly evidenced, indicating that the fractures are almost systematically initiated from such surface defects [8]. Optimization of the process route must include control of flaws. To improve the quality of the surface state of the fiber, the following should be carried out. Firstly we

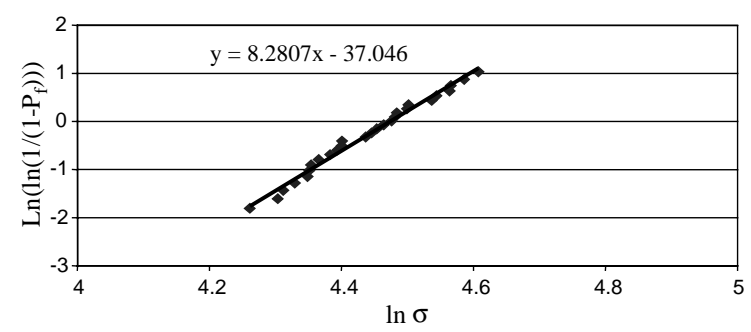

Fig. 3. Weibull modulus measurement.

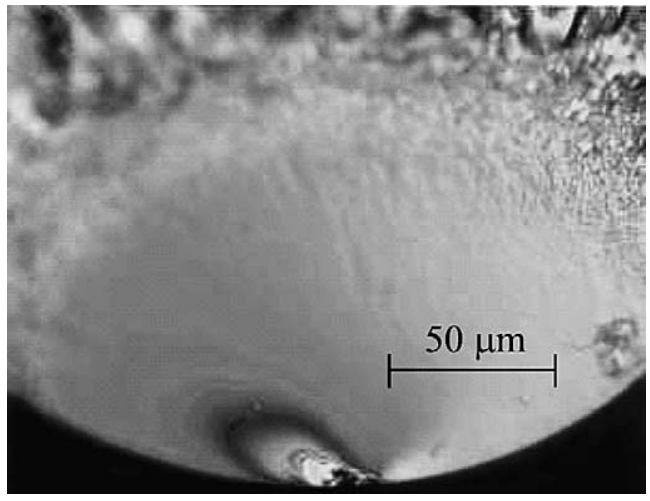

Fig. 4. Fractured surface of TAS fiber after a tensile test.

have to polish the glass rod before drawing, secondly we will have to protect the drawing tower pulley with Teflon, but overall it would be of great benefit to install the tower in a clean room or at least to use a class: 100 dust-free hood while drawing.

\section{Conclusion}

Pilot scale measurements have proved that a TAS glass fiber permits access to the absorption bands positions of classic pollutants thanks to the large window of transmission of the glass. Moreover, it has been shown that the original design of the fiber enables detection of very weak concentrations of pollutants down to $1 \mathrm{mg} \mathrm{dm}^{-3}$ (1 ppm). This pilot scale experiments have now to be confirmed in the real life conditions of landfill. For this, optical fibers must be durable under various natural working conditions in ground water. The preliminary mechanical tests demonstrate that efforts have to be made while drawing the fiber to improve their mechanical durability.

\section{Acknowledgements}

This work is supported by the environment French agency (ADEME) and takes place within the framework of the European IMSIS contract (In situ Monitoring of landfill related contaminants in Soil and water by Infrared Sensing). 


\section{References}

[1] C. Boussard-Plédel, S. Hocdé, G. Fonteneau, H.L. Ma, X.H. Zhang, K. Le Foulgoc, J. Lucas, B. Perio, J. Hamelin, Proc. SPIE 3596 (1999) 91.

[2] S. Hocdé, C. Bousard-Pledel, G. Fonteneau, J. Lucas, Solid States Sci. (2001) 279.

[3] M. Gué, V. Dupont, A. Dufour, O. Sire, Biochemistry 40 (2001) 11938.

[4] D. Naumann, in: R.A. Meyer (Ed.), Encyclopedia of Analytical Chemistry, John Wiley, Chichester, 2000, p. 102.
[5] X.H. Zhang, H.L. Ma, C. Blanchetière, J. Lucas, J. NonCryst. Solids 161 (1993) 327.

[6] S. Hocdé, C. Bousard-Pledel, G. Fonteneau, D. Le Coq, H.L. Ma, J. Lucas, J. Non-Cryst. Solids 274 (2000) 17.

[7] J.J. Mecholsky, in: Engineered Materials Handbook, vol. 4, ASM International, Metals Park, OH, 1991, p. 663.

[8] C. Pouvreau, M. Drissi-Habti, K. Michel, B. Bureau, J.C. Sangleboeuf, C. Boussard-Pledel, T. Rouxel, J.L. Adam, J. Non-Cryst. Solids 316 (2003) 131. 